\title{
Dry Matter Accumulation and Nitrogen Absorption Characteristics of Processed Pepper under Different Nitrogen Levels
}

Wang Chunping ${ }^{1 *}$, Zhang Shicai ${ }^{2 *}$, Wu Hong ${ }^{1}$, Yang Xiaomiao ${ }^{2}$, Tang Rongli ${ }^{1}$, Li Yifei ${ }^{2}$, Jiang Xiaoying ${ }^{1}$, Lei Kairong ${ }^{1}$, Huang Renzhong ${ }^{2}$, Huang Qizhong ${ }^{2} \square$, Lin Qing ${ }^{1} \square$

1 Chongqing Key Laboratory of Adversity Agriculture, Biotechnology Research Center, Chongqing Academy of Agricultural Sciences, Chongqing, 401329, P.R. China

2 Vegetable and Flower Research Institute, Chongqing Academy of Agricultural Sciences, Chongqing, 401329, P.R. China

$\bigvee$ Corresponding author email: hishqz@126.com; linqingcq@126.com

* These authors contributed equally to this work

Molecular Plant Breeding, 2021, Vol.12, No.24 doi: $10.5376 / \mathrm{mpb} .2021 .12 .0024$

Received: 24 Aug., 2021

Accepted: 31 Aug., 2021

Published: 15 Sep., 2021

Copyright $\odot 2021$ Wang et al., This article was first published in Molecular Plant Breeding in Chinese, and here was authorized to translate and publish the paper in English under the terms of Creative Commons Attribution License, which permits unrestricted use, distribution, and reproduction in any medium, provided the original work is properly cited.

Preferred citation for this article:

Wang C.P., Zhang S.C., Wu H., Yang X.M., Tang R.L., Li Y.F., Jiang X.Y., Lei K.R., Huang R.Z., Huang Q.Z., and Lin Q., 2021, Dry matter accumulation and nitrogen absorption characteristics of processed pepper under different nitrogen levels, Molecular Plant Breeding, 12(24): 1-6 (doi: $\underline{10.5376 / \mathrm{mpb} .2021 .12 .0024)}$

\begin{abstract}
In order to promote the rational use of nitrogen fertilizer, the dry matter accumulation, nitrogen absorption of processed pepper were studied by substrate culture and quantitative irrigation of nutrient solution under 6 different nitrogen levels $(60 \%, 80 \%$, $90 \%, 100 \%, 120 \%$ and $140 \%$ of the normal $\mathrm{N}$ application). It showed that, with the increase of nitrogen application, the dry weight of leaf, dry weight of fruit, dry weight of stem, dry weight of root, and dry weight of plant were increasing; The nitrogen content of each part run up to the maximum at $80 \% \sim 100 \%$ nitrogen level; There was no significant difference between the dry weight of leaf, dry weight of root, and dry weight of fruit, as well as nitrogen content and nitrogen accumulation of these parts at $90 \%, 100 \%, 120 \%$ and $140 \%$ nitrogen level. Correlation analysis showed that nitrogen accumulation showed the highest correlation with the dry weight of leaf, dry weight of stem, dry weight of fruit, dry weight of root, and dry weight of plant, but had little correlation with nitrogen content in each part. In addition, the slight difference in nitrogen content of plant at different nitrogen levels can reflect its nutritional status, while the amount of dry matter can reflect its amount of nitrogen accumulation. This study will provide theoretical reference for rational application of nitrogen fertilizer in processed pepper.
\end{abstract}

Keywords Nitrogen; Processed pepper; Dry matter; Nitrogen absorption

Pepper has the characteristics of fast growth and high yield per unit. It has a large demand for fertilizer, especially nitrogen fertilizer. However, the problem of blind and excessive application of nitrogen in production is common. Studies have shown that lower or higher than a certain range is detrimental to the yield and quality of pepper. Low nitrogen stress significantly decreased the dry weight, dry weight ratio and nitrogen content of pepper fruit (Wang et al., 2017). With the increase of nitrogen application, plant height, single fruit weight, and yield showed a trend of increasing first and then decreasing. When the nitrogen reached a certain threshold, the growth yield of pepper fruit decreased, and it was not significantly increased. The vitamin $\mathrm{C}$ content in pepper fruit under nitrogen application was higher than that without nitrogen application, but the content would decrease when nitrogen application was excessive. The nitrate content increased with the increase of nitrogen application (Yuan et al., 2006; Zhang et al., 2016). Therefore, unreasonable application of nitrogen fertilizer, especially excessive application of nitrogen fertilizer, not only does not increase yield significantly, but also causes a series of problems such as crop quality decline, nitrogen use efficiency decline and waste of resources, and environmental pollution, soil nutrient imbalance (Zhu et al., 2005).

Pepper researchers have carried out some studies on exploring the optimum nitrogen application. The results showed that the growth of Huaxi pepper variety under $3.0 \mathrm{~g} /$ hole of nitrogen application amount is normal at the growth prophase in plant height, plant width and stem diameter and the growth under $6.0 \mathrm{~g} / \mathrm{hole}$ of nitrogen application amount is normal from the growth intermediate stage in plant height, plant width and stem diameter reproductive development and slightly flower drop, which is the best growth performance in tested treatments. 
Too much and too little nitrogen application can lead to uncoordinated growth of plant height, plant width and stem diameter, and serious flower drop (Zhu et al., 2008). The plant height and branch number of Chilli pepper were the highest with nitrogen $180 \mathrm{~kg} / \mathrm{hm}^{2}$ treatment, and the yield and output value reached the highest. The highest biomass was observed with nitrogen $240 \mathrm{~kg} / \mathrm{hm}^{2}$ treatment (Han et al., 2010). The economic traits such as plant and branch number, fruit number per plant and fresh weight per fruit of pepper in Xishui County of Guizhou with nitrogen application $18 \mathrm{~kg} / 667 \mathrm{~m}^{2}$ were the best, and the yield was the highest. According to the actual production, the recommended application was $15 \sim 18 \mathrm{~kg} / 667 \mathrm{~m}^{2}$ (Deng et al., 2019). When the nitrogen application amount was $25.9 / 667 \mathrm{~m}^{2}$, the yield of the greenhouse pepper (in Turpan region of Xinjiang) reached the maximum value. The nitrogen utilization efficiency increased at first and then decreased with the increase of nitrogen application rate and the partial productivity of nitrogen fertilizer decreased significantly (Li et al., 2019).

At the previous studies, the growth, yield and quality characteristics of the processed pepper (in Chongqing) under different nitrogen application levels were studied by substrate culture. Accordingly, comprehensiving yield, quality, economic factors, and environmental protection, etc., it was preliminarily determined that the $90 \%$ nitrogen level was the optimum nitrogen fertilization scheme (Wang et al., 2019). Based on this, the dry matter accumulation and nitrogen absorption and utilization characteristics of processed pepper under different nitrogen levels were further analyzed in detail, to provide theoretical reference for rational application of nitrogen fertilizer and the realization of nitrogen reduction and efficiency increase in processed pepper.

\section{Results and Analysis}

\subsection{Dry matter accumulation of processed pepper under different nitrogen levels}

With the increase of nitrogen application levels, the dry weight of leaf, dry weight of fruit, dry weight of stem, dry weight of root, and dry weight of plant were increasing (Table 1). But there was no significant difference between the dry weight of leaf and dry weight of root at $90 \%, 120 \%$ and $140 \%$ nitrogen level. The dry weight of leaf at $90 \%$ nitrogen level was significantly higher than that at $100 \%$ nitrogen level. There was no significant difference between the dry weight of plant at $80 \%, 90 \%$ and $100 \%$ nitrogen level. And there was no significant difference between the dry weight of fruit at $90 \%, 100 \%, 120 \%$ and $140 \%$ nitrogen level.

Table 1 Dry matter accumulation of processed pepper under different nitrogen levels

\begin{tabular}{|c|c|c|c|c|c|}
\hline Nitrogen level (\%) & $\begin{array}{l}\text { Dry weight of leaf } \\
(\mathrm{g} / \text { plant })\end{array}$ & $\begin{array}{l}\text { Dry weight } \\
\text { stem (g/plant) }\end{array}$ & $\begin{array}{l}\text { of Dry weight of fruit } \\
(\mathrm{g} / \text { plant })\end{array}$ & $\begin{array}{l}\text { Dry weight of root } \\
\text { (g/plant) }\end{array}$ & $\begin{array}{l}\text { Dry weight of plant } \\
\text { (g/plant) }\end{array}$ \\
\hline 60 & $26.00 \pm 3.34 \mathrm{c}$ & $58.47 \pm 6.88 \mathrm{~b}$ & $38.53 \pm 0.59 b$ & $14.87 \pm 1.24 \mathrm{c}$ & $137.87 \pm 9.70 \mathrm{c}$ \\
\hline 80 & $38.60 \pm 5.67 \mathrm{~b}$ & $73.27 \pm 11.91 \mathrm{~b}$ & $47.77 \pm 3.28 \mathrm{~b}$ & $18.77 \pm 2.31 \mathrm{~b}$ & $178.40 \pm 20.72 b$ \\
\hline 90 & $44.73 \pm 2.25 \mathrm{a}$ & $70.83 \pm 6.96 b$ & $56.66 \pm 4.07 \mathrm{a}$ & $18.93 \pm 0.75 \mathrm{ab}$ & $191.16 \pm 8.60 \mathrm{~b}$ \\
\hline 100 & $41.73 \pm 5.10 \mathrm{~b}$ & $81.47 \pm 16.64 \mathrm{a}$ & $57.61 \pm 5.35 \mathrm{a}$ & $17.27 \pm 0.67 \mathrm{bc}$ & $198.08 \pm 17.90 \mathrm{~b}$ \\
\hline 120 & $51.67 \pm 9.50 \mathrm{a}$ & $97.73 \pm 7.05 \mathrm{a}$ & $66.91 \pm 11.75 \mathrm{a}$ & $19.33 \pm 1.39 \mathrm{a} b$ & $235.64 \pm 19.24 \mathrm{a}$ \\
\hline 140 & $55.73 \pm 9.41 \mathrm{a}$ & $95.60 \pm 6.95 \mathrm{a}$ & $66.75 \pm 5.68 \mathrm{a}$ & $21.30 \pm 1.22 \mathrm{a}$ & $239.38 \pm 5.14 \mathrm{a}$ \\
\hline
\end{tabular}

Note: Different lower case letters indicate a difference of 0.05 significant level

\subsection{Nitrogen absorption and utilization characteristics of processed pepper under different nitrogen levels}

The nitrogen absorption and utilization characteristics of different parts of processed pepper were analyzed. The results showed that with the increase of nitrogen application level, there was no significant difference between the nitrogen content of leaf, nitrogen content of fruit, nitrogen content of root and nitrogen content of plant under different nitrogen levels except for the small fluctuation of nitrogen content of stem (Table 2). With the increase of nitrogen levels, the nitrogen accumulation was increasing, but there was no significant difference between nitrogen accumulation of stem and nitrogen accumulation of plant at $80 \%, 90 \%$ and $100 \%$ nitrogen level. And there was no significant difference between nitrogen accumulation of leaf, nitrogen accumulation of fruit and nitrogen accumulation of root at $90 \%, 100 \%, 120 \%$ and $140 \%$ nitrogen level (Table 3 ). 
Table 2 Nitrogen content of processed pepper at different nitrogen levels

\begin{tabular}{llllll}
\hline Nitrogen level (\%) & $\begin{array}{l}\text { Nitrogen content } \\
\text { of leaf (\%) }\end{array}$ & $\begin{array}{l}\text { Nitrogen content } \\
\text { of stem (\%) }\end{array}$ & $\begin{array}{l}\text { Nitrogen content } \\
\text { of fruit (\%) }\end{array}$ & $\begin{array}{l}\text { Nitrogen content } \\
\text { of root (\%) }\end{array}$ & $\begin{array}{l}\text { Nitrogen content of plant } \\
(\%)\end{array}$ \\
\hline 60 & $1.31 \pm 0.20 \mathrm{a}$ & $0.76 \pm 0.09 \mathrm{~b}$ & $0.94 \pm 0.06 \mathrm{a}$ & $0.88 \pm 0.09 \mathrm{a}$ & $0.93 \pm 0.03 \mathrm{a}$ \\
80 & $1.43 \pm 0.08 \mathrm{a}$ & $0.84 \pm 0.07 \mathrm{ab}$ & $0.99 \pm 0.02 \mathrm{a}$ & $0.82 \pm 0.10 \mathrm{a}$ & $1.00 \pm 0.05 \mathrm{a}$ \\
90 & $1.41 \pm 0.13 \mathrm{a}$ & $0.83 \pm 0.09 \mathrm{ab}$ & $0.98 \pm 0.07 \mathrm{a}$ & $0.87 \pm 0.03 \mathrm{a}$ & $1.01 \pm 0.02 \mathrm{a}$ \\
100 & $1.43 \pm 0.21 \mathrm{a}$ & $0.77 \pm 0.07 \mathrm{~b}$ & $0.98 \pm 0.05 \mathrm{a}$ & $0.90 \pm 0.08 \mathrm{a}$ & $0.98 \pm 0.10 \mathrm{a}$ \\
120 & $1.29 \pm 0.09 \mathrm{a}$ & $0.83 \pm 0.03 \mathrm{ab}$ & $0.97 \pm 0.05 \mathrm{a}$ & $0.93 \pm 0.04 \mathrm{a}$ & $0.98 \pm 0.01 \mathrm{a}$ \\
140 & $1.33 \pm 0.09 \mathrm{a}$ & $0.92 \pm 0.07 \mathrm{a}$ & $0.94 \pm 0.13 \mathrm{a}$ & $0.82 \pm 0.04 \mathrm{a}$ & $1.01 \pm 0.06 \mathrm{a}$ \\
\hline
\end{tabular}

Note: Different lower case letters indicate a difference of 0.05 significant level

Table 3 Nitrogen accumulation of processed pepper under different nitrogen levels

\begin{tabular}{llllll}
\hline $\begin{array}{l}\text { Nitrogen } \\
\text { level }(\%)\end{array}$ & $\begin{array}{l}\text { Nitrogen } \\
\text { accumulation of } \\
\text { leaf }(\mathrm{g})\end{array}$ & $\begin{array}{l}\text { Nitrogen } \\
\text { accumulation of stem } \\
(\mathrm{g})\end{array}$ & $\begin{array}{l}\text { Nitrogen accumulation } \\
\text { of fruit }(\mathrm{g})\end{array}$ & $\begin{array}{l}\text { Nitrogen accumulation } \\
\text { of root }(\mathrm{g})\end{array}$ & $\begin{array}{l}\text { Nitrogen accumulation } \\
\text { of plant }(\mathrm{g})\end{array}$ \\
\hline 60 & $0.37 \pm 0.05 \mathrm{c}$ & $0.45 \pm 0.11 \mathrm{c}$ & $0.36 \pm 0.02 \mathrm{~b}$ & $0.13 \pm 0.02 \mathrm{~b}$ & $1.28 \pm 0.07 \mathrm{~d}$ \\
80 & $0.55 \pm 0.06 \mathrm{~b}$ & $0.61 \pm 0.06 \mathrm{~b}$ & $0.47 \pm 0.03 \mathrm{~b}$ & $0.15 \pm 0.02 \mathrm{ab}$ & $1.78 \pm 0.12 \mathrm{c}$ \\
90 & $0.63 \pm 0.06 \mathrm{ab}$ & $0.58 \pm 0.03 \mathrm{~b}$ & $0.57 \pm 0.07 \mathrm{a}$ & $0.16 \pm 0.01 \mathrm{a}$ & $1.93 \pm 0.12 \mathrm{bc}$ \\
100 & $0.60 \pm 0.13 \mathrm{ab}$ & $0.62 \pm 0.10 \mathrm{~b}$ & $0.56 \pm 0.02 \mathrm{a}$ & $0.15 \pm 0.02 \mathrm{ab}$ & $1.93 \pm 0.02 \mathrm{bc}$ \\
120 & $0.67 \pm 0.11 \mathrm{ab}$ & $0.81 \pm 0.04 \mathrm{a}$ & $0.65 \pm 0.13 \mathrm{a}$ & $0.18 \pm 0.01 \mathrm{a}$ & $2.30 \pm 0.14 \mathrm{a}$ \\
140 & $0.74 \pm 0.08 \mathrm{a}$ & $0.88 \pm 0.06 \mathrm{a}$ & $0.63 \pm 0.04 \mathrm{a}$ & $0.18 \pm 0.01 \mathrm{a}$ & $2.42 \pm 0.14 \mathrm{a}$ \\
\hline
\end{tabular}

Note: Different lower case letters indicate a difference of 0.05 significant level

\subsection{Correlation analysis among traits}

Correlation analysis among traits (Table 4) showed that there was significant correlation between the dry weight of each part, as well as nitrogen accumulation. And there was very significant correlation between the nitrogen accumulation and dry weight of each part. There was no significant correlation between nitrogen accumulation and nitrogen content in other parts except for nitrogen accumulation of stem and nitrogen accumulation of plant.

Table 4 Correlation analysis of dry matter accumulation, nitrogen absorption and utilization

\begin{tabular}{lllllllllllllll}
\hline Trait & $\mathrm{A} 1$ & $\mathrm{~A} 2$ & $\mathrm{~A} 3$ & $\mathrm{~A} 4$ & $\mathrm{~A} 5$ & $\mathrm{~A} 6$ & $\mathrm{~A} 7$ & $\mathrm{~A} 8$ & $\mathrm{~A} 9$ & $\mathrm{~A} 10$ & $\mathrm{~A} 11$ & $\mathrm{~A} 12$ & $\mathrm{~A} 13$ & $\mathrm{~A} 14$ \\
\hline $\mathrm{A} 2$ & $0.653^{* *}-$ & - & - & - & - & - & - & - & - & - & - & - & - \\
$\mathrm{A} 3$ & $0.665^{* *}$ & $0.834^{* *}-$ & - & - & - & - & - & - & - & - & - & - & - \\
$\mathrm{A} 4$ & $0.694^{* *}$ & $0.776^{* *}$ & $0.782^{* *}$ & - & - & - & - & - & - & - & - & - & - & - \\
$\mathrm{A} 5$ & $0.834^{* *}$ & $0.940^{* *}$ & $0.922^{* *}$ & $0.852^{* *}-$ & - & - & - & - & - & - & - & - & - \\
$\mathrm{A} 6$ & -0.180 & -0.256 & -0.041 & -0.059 & -0.183 & - & - & - & - & - & - & - & - & - \\
$\mathrm{A} 7$ & $0.544^{*}$ & 0.189 & 0.292 & 0.428 & 0.362 & -0.325 & - & - & - & - & - & - & - & - \\
A8 & 0.150 & -0.199 & -0.076 & -0.064 & -0.070 & 0.149 & 0.187 & - & - & - & - & & - & - \\
A9 & -0.119 & -0.059 & 0.068 & -0.310 & -0.060 & 0.052 & -0.212 & 0.147 & - & - & - & - & - & - \\
A10 & 0.439 & -0.142 & 0.154 & 0.198 & 0.128 & 0.420 & $0.594^{* *}$ & $0.637^{* *}$ & 0.024 & - & - & - & - & - \\
A11 & $0.934^{* *}$ & $0.564^{*}$ & $0.658^{* *}$ & $0.692^{* *}$ & $0.773^{* *}$ & 0.170 & 0.436 & 0.189 & -0.137 & $0.587^{*}$ & - & - & - & - \\
A12 & $0.769^{* *}$ & $0.919^{* *}$ & $0.812^{* *}$ & $0.820^{* *}$ & $0.936^{* *}$ & -0.345 & $0.553^{*}$ & -0.101 & -0.134 & 0.109 & $0.649^{* *}$ & - & - & - \\
A13 & $0.709^{* *}$ & $0.743^{* *}$ & $0.942^{* *}$ & $0.727^{* *}$ & $0.874^{* *}$ & -0.013 & 0.337 & 0.255 & 0.109 & 0.348 & $0.708^{* *}$ & $0.753^{* *}$ & - \\
A14 & $0.623^{* *}$ & $0.705^{* *}$ & $0.829^{* *}$ & $0.797^{* *}$ & $0.801^{* *}$ & 0.014 & 0.321 & 0.086 & 0.308 & 0.280 & $0.624^{* *}$ & $0.720^{* *}$ & $0.821^{* *}-$ \\
A15 & $0.901^{* *}$ & $0.837^{* *}$ & $0.892^{* *}$ & $0.844^{* *}$ & $0.965^{* *}$ & -0.081 & $0.504^{*}$ & 0.106 & -0.054 & 0.379 & $0.876^{* *}$ & $0.906^{* *}$ & $0.902^{* *} 0.817^{* *}$ \\
\hline
\end{tabular}

Note: **: Significant correlation at 0.01 level; *: Significant correlation at 0.05 level. A1: Dry weight of leaf; A2: Dry weight of stem; A3: Dry weight of fruit; A4: Dry weight of root; A5: Dry weight of plant; A6: Nitrogen content of leaf; A7: Nitrogen content of stem; A8: Nnitrogen content of fruit; A9: Nitrogen content of root; A10: Nitrogen content of plant; A11: Nitrogen accumulation of leaf; A12: Nitrogen accumulation of stem; A13: Nitrogen accumulation of fruit; A14: Nitrogen accumulation of root; A15: Nitrogen accumulation of plan 


\section{Discussion}

Previous studies showed that there was no significant difference in plant growth index of processed pepper between $90 \%$ of normal nitrogen application and $100 \%, 120 \%$ and $140 \%$ nitrogen application, as well as the yield characteristics of $80 \%, 90 \%$ and $100 \%$ nitrogen application. And finally, comprehensive yield, quality, nitrogen fertilizer saving, etc., it was preliminarily determined that the $90 \%$ nitrogen level was the optimum nitrogen fertilization scheme (Wang et al., 2019). Besides the yield characteristics, we analyzed each part of the plant in this study. The results showed that there was no significant difference between the dry weight of leaf, dry weight of fruit, dry weight of root, and the dry weight of plant at $90 \%, 100 \%, 120 \%$ and $140 \%$ nitrogen level except the dry weight of stem, indicating that the dry matter accumulation and yield indexes of processed pepper at $90 \%$ nitrogen application basically reached those of normal nitrogen application, which was consistent with the previous results that the $90 \%$ nitrogen level was the optimum nitrogen fertilization scheme.

Yue et al. (2014) showed that the total nitrogen content of pepper plants increased with the increase of nitrogen application and reached the maximum under the appropriate nitrogen application treatment. This study showed that the nitrogen content of leaf, fruit, root, and plant run up to the maximum at $80 \% \sim 100 \%$ nitrogen level except stem, which also showed that $90 \%$ nitrogen level was close to the theoretical optimum nitrogen level. It is worth noting that there was no significant difference in nitrogen content in the same part under different nitrogen application levels. And there was no significant difference between nitrogen content of leaves and fruits of most pepper genotypes even under $20 \%$ of that normal nitrogen treatment (Wang et al., 2018), indicating that the nitrogen content difference of pepper plants under different nitrogen application levels was very slight. The nitrogen content could sensitively reflect the nutritional status, which provided the basis for establishing the critical nitrogen concentration dilution curve by using the relationship between content of nitrogen and dry matter. Correlation analysis showed that nitrogen accumulation significantly positively correlated with dry weight, whereas no significant correlation was found with nitrogen content. Wang et al. (2019) also found that nitrogen accumulation significantly positively correlated with dry matter accumulation in different organs of peanut, whereas no significant correlation was found with nitrogen content. Therefore, the amount of nitrogen accumulation in crops is mainly reflected by the accumulation of dry matter, rather than nitrogen content, because the difference in plant nitrogen content between different genotypes of the same crop is not significant under different nitrogen levels (Cao et al., 2019). In addition, the slight difference in nitrogen content of plant at different nitrogen levels can reflect its nutritional status, while the amount of dry matter can reflect its amount of nitrogen accumulation.

Around the issue of how to rationally apply nitrogen fertilizer, scholars in China and abroad have carried out a lot of basic research and made some progress. Most noteworthy is the establishment of critical nitrogen concentration dilution curves in different ecological regions and varieties of major food crops such as rice, wheat, and maize, reflecting the relationship between crop nitrogen concentration and plant dry matter (Ata-Ul-Karim et al., 2013; Ma et al., 2017; Lu et al., 2019), as well as vegetables such as tomato, cucumber, and garlic (Du et al., 2016; Zhao et al., 2018; Mou et al., 2019). There is no relevant research report in pepper, mainly due to the lack of basic research on nitrogen absorption and utilization of pepper and the lack of systematic data.

This study will provide theoretical reference for establishing the critical nitrogen concentration dilution curve and promoting the rational application of nitrogen fertilizer in processed pepper. However, only the nitrogen utilization characteristics of processed pepper at mature stage were analyzed. To design a complete and rational nitrogen application scheme, it is necessary to understand the dynamic characteristics of nitrogen utilization during the whole growth and development period of plants. The team will gradually carry out such research work in the future.

\section{Materials and Methods}

\subsection{Experimental materials}

The processed single Chao-tian Pepper Variety 'Yanjiao 425', bred by Vegetable and Flower Research Institute, Chongqing Academy of Agricultural Sciences $\left(29^{\circ} 5^{\prime} \mathrm{E}, 106^{\circ} 4^{\prime} \mathrm{N}\right)$. 


\subsection{Experimental methods}

The substrate was cultivated in greenhouse, and the volume ratio of coir: perlite: vermiculite was 5:3:2. Nutrient solution under 6 different nitrogen levels $(60 \%, 80 \%, 90 \%, 100 \%, 120 \%$ and $140 \%$ of the normal $\mathrm{N}$ application) were set (Wang et al., 2019), with 3 replicates per treatment and 28 plants per replicate. Nutrient solution formula and specific nutrient solution scheme refer to the previous research of the team (Wang et al., 2017; 2018; 2019).

Picking in batches at maturity. The red peppers were picked once every $10 \mathrm{~d}$, and the number and weight of red peppers in each plot were counted for 3 times. The fruit was washed with tap water after picking. De-enzyme at $105^{\circ} \mathrm{C}$ for $30 \mathrm{~min}$, then dried to constant weight at $70^{\circ} \mathrm{C}$, and weighed the dry weight of the fruit.

After each fruit picking, 4 representative plants were selected from each plot to determine dry weight of leaf, dry weight of stem, dry weight of root, nitrogen content of leaf, nitrogen content of stem, nitrogen content of fruit and nitrogen content of root. The specific sampling and determination methods were referred to the previous study of the team (Wang et al., 2017; 2018; 2019). Then calculated the dry weight of plant, root-shoot ratio, nitrogen content of plant, nitrogen accumulation of leaf, nitrogen accumulation of stem, nitrogen accumulation of fruit, nitrogen accumulation of root and nitrogen accumulation of plant:

Dry weight of plant $(\mathrm{g})=$ dry weight of leaf $(\mathrm{g})+$ dry weight of stem $(\mathrm{g})+$ dry weight of fruit $(\mathrm{g})+$ dry weight of root $(\mathrm{g})$;

Nitrogen accumulation of plant $(\mathrm{g})=$ nitrogen accumulation of leaf $(\mathrm{g})+$ nitrogen accumulation of stem $(\mathrm{g})+$ nitrogen accumulation of fruit $(\mathrm{g})+$ nitrogen accumulation of root $(\mathrm{g})$;

Nitrogen content of plant $\%=$ nitrogen accumulation of plant $(\mathrm{g}) / \mathrm{dry}$ weight of plant $(\mathrm{g}) \times 100 \%$.

\subsection{Data processing}

Excel 2010 software was used for data processing. SPSS19.0 software was used for statistical analysis. And LSD test was used for statistical analysis of significant difference.

\section{Authors' contributions}

WCP and ZSC designed and carried out the study, completed data analysis, and drafted the manuscript. WH, YXM, TRL, LYF, and JXY participated in the design of the study and performed the statistical analysis. HQZ, LQ, LKR, and HRZ conceived of the project, directed the design of the study, data analysis, draft, and revision. All authors read and approved the final manuscript.

\section{Acknowledgments}

This study was supported by the Special Fund Project for Construction of National Modern Agricultural Industry Technology System (CARS-24-A-04), Special Project of Performance Incentive and Guidance for Scientific Research Institutions in Chongqing (cstc2018jxj180013), and Special Key Projects of Technological Innovation and Application Development in Chongqing (cstc2019jscx-gksbX0123).

\section{Reference}

Ata-Ul-Karim S.T., Yao X., Liu X.J., Cao W.X., and Zhu Y., 2013, Development of critical nitrogen dilution curve of Japonica rice in Yangtze River Reaches, Field Crops Research, 149: 149-158 https://doi.org/10.1016/i.fcr.2013.03.012

Cao C.Q., Zhang G.B., Hu L.L., Qiang H.R., Ma G.L., Du M.X., and Li Y.T., 2019, Studies on nitrogen distribution characteristics of capsicum organs and matrix nitrogen transportation law by ${ }^{15} \mathrm{~N}$ isotope tracing technique, Huabei Nongxuebao (Acta Agriculturae Boreali-Sinica), 34(2): 171-177

Deng X.Q., Zhang D.Q., Fan G.G., Li W.Y., Gong X.F., and Li T.S., 2019, Effect of nitrogen application on economic characteristics, yield and efficiency of nitrogen fertilizer utilization of chili pepper, Gengzuo Yu Zaipei (Tillage and Cultivation), 39(1): 32-34

Du Y.D., Cao H.X., Gu X.B., and Wang P., 2016, Critical nitrogen dilution curve and nitrogen index for soiless Tomato, Jieshui Guangai (Water Saving Irrigation), (9): 1-7, 11

Han M.Z., Zu Y.Q., Li Y., and Wu B.Z., 2010, Effects of levels of nitrogen fertilizer application on the growth yield and quality chilli pepper, Nongye Huanjing Kexue Xuebao (Journal of Agro-Enviroment Science), 29(3): 32-35

Li H.F., Zhang C.M., Liu Z.G., Guo H.M., Luerziyeguli M., and Huxidan M., 2019, Effects of nitrogen fertilizer application rate on yield, economic benefit and nitrogen use efficiency of greenhouse pepper (Capsicum annuum L.), Xinjiang Nongye Kexue (Xinjiang Agricultural Sciences), 56(8): 1502-1509 
Lu X.J., Guo X.Y., Wen W.L., and Yu Z.T., 2019, Development and validation of critical nitrogen dilution curve for spring maize in northeast China, Zhongguo Nongye Keji Daobao (Journal of Agricultural Science and Technology), 21(11): 77-83

Ma X.J., Zhang X.T., Huang Y.F., and Ye Y.L., 2017, Establishment and application of critical nitrogen dilution curve for wheat based on leaf dry matter, Zhiwu Shengli Xuebao (Plant Physiology Journal), 53(7): 1313-1321

Mou S.W., Xie J., Luo C., Liu T.N., Yang B.P., Han Q.F., and Liu X.X., 2019, Establishment and verification of critical nitrogen concentration dilution curve of garlic in Guanzhong plain, Nongye Gongcheng Xuebao (Transactions of the Chinese Society of Agricultural Engineering), 35(19): 126-133

Wang C.P., Zhang S.C., Lei K.R., Huang R.Z., Lv Z.H., Wu H., Jiang X.Y., Li Y.F., Tang R.L., Huang Q.Z., and Lin Q., 2017, Studies of indexes and evaluation of low nitrogen tolerance of pepper at seedling stage, Yuanyi Xuebao (Acta Horticulture Sinica), 44(12): 2318-2326

Wang C.P., Zhang S.C., Huang R.Z., Jiang X.Y., Li Y.F., Wu H., Lei K.R., Yang X.M., Lü Z.H., Huang Q.Z., and Lin Q., 2018, Effects of low nitrogen stress on the growth, material accumulation, nitrogen uptake and utilization efficiency of soilless cultivated pepper, Lajiao Zazhi (Journal of China Capsicum), 16(1): $22-28$

Wang C.P., Zhang S.C., Huang R.Z., Tang R.L., Li Y.F., Wu H., Jiang X.Y., Yang X.M., Lei K.R., Huang Q.Z., Lin Q., 2019, Molecular Plant Breeding , http://kns.cnki.net/kcms/detail/46.1068.S.20190410.1202.014.htm

Wang C.X., Zheng Z.L., Ling F., Wang P., Jiao Y.L., Feng H., Zheng Y.M., and Wang C.B., 2019, Study on related indexes of nitrogen utilization characteristics for different peanut varieties, Henongxue Bao (Journal of Nuclear Agricultural Sciences), 33(12): 2421-2429

Yuan Z.H., Ding Z.Y., and Cai Y.P., 2006, Effects of nitrogen application on yield and nitrate accumulation in peppers, Lajiao Zazhi (Journal of China Capsicum), 4(2): 22-23, 28

Yue Y.B., Nie K.Y., Li R.J., Sun C.Q., Peng Z.L., and Zhao Z.Y., 2014, Correlation of total nitrogen content in overground part of pepper at different nitrogen application level with canopy spectral reflectance, Guizhou Nongye Kexue (Guizhou Agricultural Sciences), 42(11): 244-247

Zhang Z.H., Zhou J., Zhang H.Q., Deng X.F., Zhang P.H., and Zhao Z.Q., 2016, Effects of different application of nitrogen Fertilizers on the yield and quality of pepper, Hubei Nongye Kexue (Hubei Agricultural Scienc), 55(16): 4110-4112, 4116

Zhao M.H., Wang A.H., Zhao W., Zhang Z.P., Jiang J.Z., Fang S.L., and Miao M.M., 2018, Simulation of critical nitrogen concentration and nitrogen nutrition index in greenhouse cucumber, Zhongguo Turang Yu Feiliao (Soils and Fertilizers Sciences in China), (6): 141-147

Zhu J.H., Li X.L., Christie P., and Li J.L., 2005, Environmental implications of low nitrogen use efficiency in excessively fertilized hot pepper (Capsicum frutescens L.) cropping systems, Agriculture, Ecosystems and Environment, (111): 70-80 https://doi.org/10.1016/j.agee.2005.04.025

Zhu Q., Mo B.L., and Zhang E.R., 2008, Effects of different nitrogen application amount on growth and flower drop of pepper, Guizhou Nongye Kexue (Guizhou Agricultural Sciences), 36(1): 114-115 